\title{
Tomada de decisão financeira: aplicando o processo orçamentário
}

\author{
Making financial decision: applying budget process
}

\section{Resumo}

Filipe Prado Macedo da Silva ${ }^{\mathrm{I}}$

Este artigo aborda a dinâmica da decisão financeira e o processo orçamentário no âmbito das empresas. Em vista da globalização e liberalização financeira, a tomada de decisão financeira ganhou importância dentro do processo de gestão empresarial, sobretudo quando afeta o fluxo de caixa e os relatórios contábeis. Algumas empresas - como a M\&S Comercial - utilizam o processo orçamentário como ferramenta de apoio na gestão financeira. O orçamento serve de "guia" para os gestores da empresa. No estudo de caso, constatamos que a empresa melhorou seu desempenho econômico-financeiro ao integrar o processo orçamentário na dinâmica da tomada de decisão financeira.

Palavras-chave: Finanças; Decisão Financeira; Processo Orçamentário.

\begin{abstract}
This article discusses the dynamics of financial decision and budgeting process within companies. In view of globalization and financial liberalization, financial decision making has gained importance within the business process management, especially when it affects cash flow and accounting reports. Some companies - like M\&S Commercial - use the budget process as a support tool in financial management. The budget serves as a "guide" for the managers. In the case study, we found that the company has improved its financial performance by integrating the budgeting process in the dynamics of financial decision making.
\end{abstract}

Keyword: Finance; Financial Decision; Budget Process.

1filipe.prado@filipeprado.ecn.br, Brasil. Professor Assistente da Associação Catalana de Educação - CESUC. Mestrando em Economia na Universidade Federal de Uberlândia - UFU. Av. João Naves de Ávila, 2121, Campus Santa Mônica, Bloco J, Sala 1J155, Santa Mônica, CEP: 38400-902 - Uberlândia, MG - Brasil.

Recebido em 02.11.2010

Aprovado em 07.11.2013

Revista Administração em Diálogo ISSN 2178-0080

Programa de Estudos Pós-Graduados em Administração

Pontifícia Universidade Católica de São Paulo 


\section{Introdução}

Este artigo abordará sobre o desempenho do processo orçamentário na dinâmica da tomada de decisão financeira. $\mathrm{O}$ estudo elaborado é de importância para o meio acadêmico e empresarial, pois testifica a viabilidade da integração do orçamento empresarial com a decisão financeira. Verificamos com um estudo de caso, que a empresa M\&S Comercial, ao implantar o orçamento em suas decisões financeiras, reduziu em 9o\% seus custos financeiros.

Antes da implantação do orçamento, a empresa sofria com a sazonalidade do mercado da construção civil, prejudicando o fluxo de caixa, obrigando-a a se financiar a curto e médio prazo, incorrendo em gastos com juros, impostos e tarifas de serviços financeiros, impactando diretamente no resultado líquido do negócio. Em 2003, por falta de planejamento, a empresa incorreu em despesas financeiras, de aproximadamente R\$ IOo mil, além de passar por graves problemas de capital de giro, ameaçando a sobrevivência do negócio.

Apesar de o trabalho utilizar uma pequena empresa como fonte de pesquisa e estudo, tais resultados podem ser replicados e utilizados como estimulador para o desenvolvimento de novos trabalhos e pesquisas científicas sobre o assunto. Este artigo objetiva contribuir para o refinamento das decisões financeiras, sobretudo as decisões de investimento e as decisões de financiamento - com aplicações integradas ao processo orçamentário empresarial.

Os problemas vinculados ao tema abordado são os seguintes: (I) Como evitar déficits no fluxo de caixa?(2) Como aproveitar e utilizar os superávits do fluxo de caixa?(3) Como reduzir os gastos com despesas financeiras?(4) Como equilibrar o fluxo de caixa, diante das sazonalidades, ao longo de I2 meses?A problemática do trabalho adota a seguinte lógica e interdependência: a sazonalidade é inerente a qualquer tipo de negócio. Esse movimento no volume das vendas cria flutuações financeiras no negócio.

Estes problemas exigem do gestor mais planejamento e controle das informações, para subsidiar os novos movimentos estratégicos. Em situações de déficits, o gestor terá que tomar decisões de financiamento. E, em caso de superávits, o gestor toma decisões de investimento. Nestes dois casos, é preciso avaliar as receitas e despesas financeiras. 
Além disso, situações de prejuízo sucessivo podem inviabilizar o negócio no curto e médio prazo.

Com base na discussão acima, o problema prioritário do trabalho é saber: como evitar déficits no fluxo de caixa e reduzir as despesas financeiras? Este problema é importante, uma vez, que afeta a atuação de qualquer empresa. O fluxo de caixa representa a "oxigenação" em curto prazo. A empresa pode ficar inviabilizada de produzir, comprar e vender se não tiver um bom planejamento empresarial para a tomada de decisões financeiras, prejudicando assim toda a sua cadeia operacional.

$\mathrm{Na}$ visão acadêmica, o trabalho contribui para a demonstração de que ferramentas de gestão podem ter eficiência quando integradas as decisões financeiras da empresa. Do ponto de vista empresarial, o material contribui para um melhor resultado e controle financeiro do negócio, conforme explanado no estudo de caso. Sem dúvida nenhuma, melhores resultados financeiros ajudam a gerar mais desenvolvimento, emprego, renda e produção.

Nos aspectos metodológicos, usaremos na coleta de dados os seguintes autores: Assaf Neto (1997), que apresenta como as decisões financeiras são tomadas nas empresas modernas; Lunkes (2003), que delineia os processos orçamentários e seus principais objetivos; e Pyhrr (198I) que trabalha o 'orçamento base zero', explicando o objetivo e o método de elaboração.

Para analisar as informações, e assim propor a modelagem da solução mais viável para o problema prioritário, usaremos o seguinte protocolo: (I) Verificar os resultados da empresa antes do processo orçamentário; (2) Avaliar a implantação do orçamento; (3) Verificar o ganho de desempenho após a implantação orçamentária; (4) Verificar as tomadas de decisões antes do orçamento; (5) Analisar os dados do orçamento para tomar decisões financeiras; (6) Relatar os resultados das decisões financeiras com orçamento e comparar com as decisões financeiras sem orçamento; (7) Concluir relacionando os ganhos da integração orçamento-finanças.

A verificação da viabilidade da conexão "orçamento-finanças" será feita com base na experiência realizada pela $M \& S$ Comercial - que durante cinco anos - integrou o orçamento empresarial com as decisões financeiras. Os critérios de verificação serão os seguintes: (I) O orçamento ajudou no controle financeiro?(2) O orçamento pode prever 
movimentos futuros?(3) É possível antecipar decisões financeiras?(4) Após a implantação, a empresa apresentou melhores resultados?(5) É possível reduzir os custos financeiros com o orçamento?

O trabalho seguirá a estrutura lógica, a saber: (I) A dinâmica das decisões financeiras nas empresas; (2) O processo orçamentário como ferramenta de gestão; (3) Estudo de Caso - Aplicando o processo orçamentário nas decisões financeiras; e (4) Considerações Finais.

\section{A dinâmica das Decisões Financeiras nas Empresas}

\section{A importância das finanças no cenário global}

As decisões financeiras são tomadas nas organizações empresariais de forma contínua, inevitável e integradas ao cenário de desenvolvimento mundial. A nova ordem econômica internacional impôs as empresas um ambiente complexo e arriscado em termos de decisão. Segundo Baumann (i996), "[...] o mundo sem fronteiras criou conformidade não apenas nos movimentos financeiros, mas também nas estruturas produtivas $[\ldots] "$.

No centro das mudanças, a supremacia dos mercados - por meio do capitalismo liberal -transformou para sempre os interesses das economias mundiais. O capital passou a ditar costumes e regras, ganhou importância nas relações sociais e políticas, e tornou-se presente em todas as relações econômicas.Sem dúvida nenhuma, “[...] constantes alterações nas regras do sistema financeiro internacional reforçam o argumento de que o 'mundo' financeiro controla o 'mundo' real” (EICHENGREEN, 2003).

Em outras palavras, as questões financeiras permeiam nossas relações e ocupam grande parte de nossas preocupações atuais. A globalização financeira, a liberalização cambial e a vulnerabilidade externa são temas do dia-a-dia de empresas, de governos e de cidadãos. A importância das finanças no mundo moderno é notável. Contudo, essa integração globalizada trouxe incertezas e dificuldades financeiras até então desconhecidas das nações.

Segundo Assaf Neto (I997), “[...] desequilíbrios nas taxas de juros, fragilização 
das contas públicas, desajustes de mercado, ausência de poupança, intervenções freqüentes nas regras, entre outros [...]" têm dificultado o processo decisório financeiro, exigindo uma maior capacidade analítica e quantitativa. Neste contexto, a questão-chave é saber como preservar - tanto no domínio público como privado - o capital.

A gestão financeira ganhou considerável importância nos últimos 20 anos. Com a internacionalização dos produtos bancários, “[...] conceitos financeiros consagrados em outros ambientes [...] encontraram enormes dificuldades de adaptação em nossa [nova] realidade empresarial, demandando um conjunto de ajustes e reflexões (ASSAF NETO, I997). O gestor financeiro passou a ser mais exigido:

Praticamente tudo o que se pensa dentro de uma corporação tem um impacto financeiro no orçamento, sendo necessário uma avaliação profunda no que diz respeito ao conhecimento, orientação e uso dessa ferramenta de auxílio [gestão financeira] no que se refere à tomada de decisão (PINA, 2008, p. I).

A gestão financeira assumiu um importante papel na sobrevivência e na realização dos objetivos das empresas. Todos os agentes econômicos foram afetados pelas transformações criadas pela globalização.A finalidade deste trabalho é avaliar as modificações financeiras ocorridas nas empresas - excluindo governos e famílias. Essa delimitação é importante para refletirmos sobre os aspectos mais críticos.

\section{O novo enfoque da administração financeira}

Praticamente todos os indivíduos e organizações ganham ou levantam dinheiro e gastam ou investem dinheiro. Finanças são os processos pelos quais o dinheiro é transferido (por meio de financiamento e de investimento) entre empresas, indivíduos e governo (GITMAN; MADURA,2OO3, p. 2).

É por isso, que a gestão financeira é uma forte ferramenta de enfoque sistemático, para avaliar "as decisões financeiras que influenciam o valor da empresa, conforme refletido no preço de suas ações [...]" (GITMAN; MADURA, 2003). De acordo com Assaf Neto (2006), “[...] a gestão financeira cuida de planejamento, investimento, crescimento e financiamento".O conceito de administrar envolve "decidir", e a preservação da empresa depende da qualidade das decisões.

Neste contexto, espera-se que os gerentes financeiros optem por decisões que maximizem o valor da empresa "gerando maior rentabilidade sobre o investimento efetuado por indivíduos e instituições" (SECURATO, 200I). Dessa forma, "a área 
financeira passou de uma postura mais conversadora e de absoluta aceitação dos fatos para uma posição bem mais eficiente [...]" (ASSAF NETO, 2006). Além disso, a globalização financeira obrigou a gestão financeira a assumir maiores níveis de responsabilidade.

A evolução financeira abriu os olhos do gerente financeiro, “[...] para a questão de considerar mais profundamente a empresa.” (PINA, 2008). O resultado disso é que a função financeira é continuamente conduzida e integrada com outras funções da empresa. Isso proporciona aos gerentes financeiros, decisões de financiamento e investimento consistentes com os planos estratégicos e as metas orçamentárias do negócio, como um todo

Os fatores-chaves da decisão financeira: investimento e financiamento

Qualquer que seja a natureza da atividade operacional, uma empresa é avaliada como tomadora de duas decisões: decisão de investimento - aplicação de recursos - e decisão de financiamento - captação de recursos" (ASSAF NETO, I997). Alguns autores demonstram que as empresas tomam uma terceira decisão: “[...]conhecida por decisão de dividendos [...]" (GITMAN; MADURA, 2003). Entretanto, incluiremos a decisão de dividendos na área de financiamento.

As decisões de investimento envolvem o processo de análise, avaliação, identificação e seleção das alternativas de aplicação dos recursos. As decisões de financiamento permeiam a definição da natureza dos fundos captados, ou seja, "[...] a estrutura das fontes de capital [...]" (GITMAN; MADURA, 2003). Essas duas decisões são tomadas de forma contínua e integradas entre si. Vale lembrar, que essas decisões não se limitam ao financiamento e investimento inicial:

A maioria das empresas necessita de financiamento ao serem criadas, mas a função financeira da empresa não está limitada [ou, restrita] a esse financiamento inicial (GITMAN; MADURA,2OO3, p. 4).

Além disso, “[...] enquanto as decisões de financiamento descrevem as taxas de retorno exigidas pelos detentores de capital, as oportunidades de investimento centram suas preocupações nos retornos esperados.” (ASSAF NETO, I997). Isso significa que existe uma relação inversa entre a taxa de retorno esperada dos investimentos e o custo real do financiamento, levando a uma separação dos estudos para fins didáticos. 


\section{Decisões de investimento}

Segundo Bruni e Famá (2007), “[...] os investimentos podem ter duas naturezas distintas: investimento financeiro [...] ou investimento de capital”. Os investimentos financeiros são as compras de títulos e valores mobiliários negociados em bolsas de valores. Na categoria dos investimentos de capital estão os gastos com maquinário, planta industrial,etc. Para ambos os casos, "a análise [...] consiste em análise da projeção de fluxos de caixa” (BRUNI; FAMÁ, 2007).

O processo de avaliação da decisão de investimento consiste em duas análises: uma quantitativa e outra qualitativa. A análise quantitativa consiste em "[...] estimar os fluxos de caixa futuros dentro do período de projeção" (BRUNI; FAMÁ, 2007). A questão qualitativa envolve a racionabilidade do processo, e que "[...] os indivíduos envolvidos na decisão financeira maximizem suas satisfações [...]” (GITMAN; MADURA, 2003).

A análise qualitativa é estritamente subjetiva. Cabe a cada empresa analisar as suas experiências para a execução dos projetos de investimentos. Já a análise quantitativa é obtida por meio de fórmulas financeiras. Consiste basicamente em, três fórmulas:(I) cálculo do payback; (2) cálculo do valor presente líquido (VPL); e (3) cálculo da taxa interna de retorno (TIR). Além disso, considera-se uma análise de taxas de juros e seleção de projetos.

O propósito das fórmulas financeiras é identificar o nível de retorno do capital investido. Segundo Gitman (2003), "os investimentos feitos pela empresa destinam-se a gerar fluxos de caixa que ofereçam retorno sobre os investimentos". O detalhamento numérico do projeto permite estimarmos se o investimento atenderá as metas estabelecidas da empresa.

Hoje, raramente os gerentes financeiros executam cálculos manuais, principalmente da TIR, “[...] que envolvia procedimentos empíricos do tipo 'tentativa e erro"” (BRUNI; FAMÁ, 2007).Na prática, todos os cálculos financeiros são executados por meio de calculadoras, planilhas eletrônicas e sistemas.Isso gera resultados eficientes para os tomadores de decisões. 


\section{Decisões de financiamento}

Gitman e Madura (2003) dizem que "quando as empresas obtêm recursos, seu financiamento pode ser classificado como financiamento de dívida ou de capital próprio”. No financiamento de dívida, os fundos são obtidos por meio de empréstimos bancários ou emissão de títulos de dívida (privada). No financiamento de capital próprio, os fundos são obtidos “[...] em troca de participação na empresa” (GITMAN, MADURA 2003).

Em termos operacionais, as decisões de financiamento são mais simples do que as de investimento. Já, em termos de importância, é igualmente essencial para a sobrevivência do negócio.As decisões de financiamento enfocam o lado direito do balanço patrimonial da empresa, notadamente, o passivo de curto e de longo prazo. O detalhe é que, independente do tipo de financiamento, todos geram no curto e no longo prazo endividamento.

Por isso, as decisões de financiamento são importantíssimas para o surgimento, a manutenção e o crescimento de qualquer negócio. Os gerentes financeiros precisam ser cautelosos - e até mesmo conservadores - em suas decisões de financiamento. Dessa forma, precisam trabalhar com o máximo de atenção, observando os seguintes aspectoschaves:

Em primeiro lugar, devem ser estabelecidos os níveis de financiamento de curto e longo prazos. Uma segunda preocupação, igualmente importante, é determinar as melhores fontes de financiamento (GITMAN; MADURA 2O03, p. 6).

O primeiro aspecto-chave da análise do financiamento é o seu custo financeiro. Qual a taxa de juros? Existem impostos? Para responder a essas perguntas, os gerentes financeiros precisam avaliar:(I) disponibilidade de crédito; (2) concorrência do setor bancário; (3) retorno do negócio; (4) risco de inadimplência; (5) taxa de juros; (6) nível de atividade da economia; e (7) vantagens competitivas.

O segundo aspecto do financiamento refere-se ao período da operação. É importante a empresa definir se o “[...] financiamento será de curto prazo (até ı2 meses) ou de longo prazo (mais de I2 meses)" (GITMAN; MADURA, 2003). Isso vai depender do objetivo.

Por fim, o terceiro aspecto-chave refere-se ao tipo do financiamento. Conforme Gitman (2003) existem dois tipos: "financiamento de dívida ou de capital próprio". O gestor financeiro precisa encontrar a melhor composição para o endividamento. É 
importante avisar, que o financiamento por capital próprio proporciona lucros aos investidores. Contudo, o financiamento por dívida é menos arriscado para os acionistas do que o por capital próprio, ou seja, o financiamento por dívida utiliza os recursos de terceiros.

\section{A dinâmica das decisões financeiras}

A dinâmica das decisões financeiras está “[...] voltada à satisfação do retorno exigido por seus proprietários" (PINA, 2008). Assaf Neto (I997) completa que “[...] todo o arcabouço conceitual das decisões financeiras tem sua avaliação fundamentada pelos resultados operacionais." Isso significa que a qualidade das decisões financeiras são medidas através de seu desempenho econômico.

É por isso, que as decisões financeiras são executadas com base em previsões e cálculos, pois pode afetar diretamente o indicador de retorno sobre o total investido (ROI), o retorno sobre o patrimônio e o custo financeiro - modificando assim o resultado operacional da empresa. Assaf Neto (I997) acrescenta:

O indicador do retorno sobre o total investido (ROI) é medido, basicamente, pela relação entre o resultado gerado pelos ativos e o montante dos investimentos (ASSAF NETO, 1997, p. 3).

Assim, os gerentes financeiros devem se preocupar em considerar dois fatores: (a) os impactos econômicos e (b) os impactos financeiros. Ambos acontecem como resultado da dinâmica das decisões financeiras.Assaf Neto (1997) destaca que "[...] nenhuma empresa pode escapar de conhecer os efeitos colaterais decorrentes das decisões financeiras [...]”. Vale lembrar, que os resultados obtidos são registrados pela contabilidade.

Por exemplo, o impacto econômico gera alterações no valor da empresa, através de movimentos no patrimônio líquido do negócio. No caso do impacto financeiro gera alterações no equilíbrio do caixa - termômetro de liquidez do negócio. Sendo assim, é fundamental a empresa manter "sua contabilidade ajustada aos objetivos gerenciais" (ASSAF NETO, I997). As empresas utilizam os demonstrativos contábeis para avaliar o desempenho do negócio.

No geral, os gerentes financeiros utilizam: o demonstrativo de resultado (DRE), o balanço patrimonial (BP), o demonstrativo das mutações do patrimônio e o 
demonstrativo dos fluxos de caixa, para monitorar o comportamento do negócio. Estes instrumentos contábeis são elaborados mensalmente. O ideal é que sejam demonstrações transparentes e fidedignas. Por fim, o objetivo é que reproduzam toda a dinâmica das decisões financeiras.

Neste contexto, concluímos ao lado de Smith (I98I) com a proposição de que, “[...] dadas às condições adequadas às decisões do empresário visam à satisfação de seus próprios interesses [...]”. Ou seja, a dinâmica das decisões financeiras conduz a empresa, isoladamente, a maximizar a sua opulência e que isso "[...] leva, involuntariamente, ao progresso da nação” (SMITH, I98I). Isso corrobora a idéia de que as empresas buscam financiamentos que minimizem os custos e investimentos que maximizem os retornos.

\section{O Processo Orçamentário como Ferramenta de Gestão}

\section{Histórico do orçamento}

A importância de orçar é tão antiga quanto à humanidade. Segundo Lunkes (2003), "[...] os homens das cavernas precisavam prever a necessidade de comida para os invernos; com isso desenvolveram práticas antigas de orçamento [...]”. Entretanto, os procedimentos hoje conhecidos no campo orçamentário tiveram sua origem no século XIX.

Nesse período surgiram os princípios do sistema de contabilidade uniforme, a idéia de um ano fiscal padrão, as primeiras convenções de tempo para prestação de contas e o sistema de auditorias. De fato, o orçamento passou a ser considerado o "[...] principal instrumento de política do governo" (LUNKES, 2003). Mas, foi no século XX, que o orçamento ganhou um destaque maior nos corredores dos governos e das empresas.

Segundo Zdanowicz (I989), “[...] em I92I, o Congresso Norte-Americano aprovou a obrigatoriedade do orçamento público anual.” No setor privado, relatos indicam que “[...] em r9ı9, Brown (Dupont) foi o primeiro a utilizar o orçamento [...]" (ZDANOWICZ, I989). No Brasil, o orçamento só ganhou destaque a partir de I970, quando boa parte das grandes empresas passou a adotá-lo com mais freqüência em suas atividades de gestão. 
Ao longo dos anos, o orçamento foi adaptando-se e acompanhando as tendências das teorias de gestão. Isso proporcionou o surgimento de uma série de métodos orçamentários, como: orçamento empresarial, orçamento contínuo, orçamento base zero, orçamento flexível, orçamento por atividades e orçamento perpétuo.

Essa evolução continuada - nos últimos Ioo anos - transformou o orçamento em uma formidável ferramenta de gestão pública e privada. Hoje, o orçamento está integrado à alta administração e a contabilidade. O resultado é um moderno processo orçamentário ampliado e abrangente - em todos os aspectos organizacionais.

\section{O processo orçamentário}

Para Baumann (I996), “[...] o orçamento pode ser sumarizado como um plano de ação detalhado, desenvolvido e distribuído como um guia para as operações e como base parcial para subseqüente avaliação de desempenho". Na prática, o orçamento reúne um conjunto de previsões quantitativas apresentadas de forma estruturada.

O processo orçamentário é a forma como a empresa faz o orçamento. Esse ritual ou ciclo orçamentário varia de empresa para empresa - conforme a cultura corporativa.Além disso, o orçamento preocupa-se com a execução do planejamento estratégico - que envolve muitas vezes o incremento de novos produtos, canais de distribuição, entre outros.

\section{A estrutura básica do orçamento}

Segundo Lunkes (2003), “[...] a estrutura básica do orçamento é formada a partir das projeções financeiras dos orçamentos individuais de cada unidade da empresa e num conjunto de orçamentos para um determinado período [...] abrangendo o impacto tanto das decisões operacionais quanto das decisões financeiras.” A Figura I, de forma esquemática e simples, retrata o processo orçamentário empresarial.

Horngren (1997) completa que, "para atingir as metas prescritas no orçamento geral, uma empresa deve coordenar os esforços dos seus empregados". Cada gerente é encarregado de um centro de responsabilidade. Lunkes (2003) comenta, “[...] a responsabilidade, pode ser definida por atividade, processo, unidade de negócio ou até conta contábil.” 
Assim, as empresas podem maximizar as vantagens do orçamento, transformando-o no principal sistema de controle gerencial, minimizando as limitações. Além disso, é notório que as recentes evoluções - contábeis e tecnológicas - reduziram as ineficiências.

Figura I - O Esquema Global do Processo Orçamentário

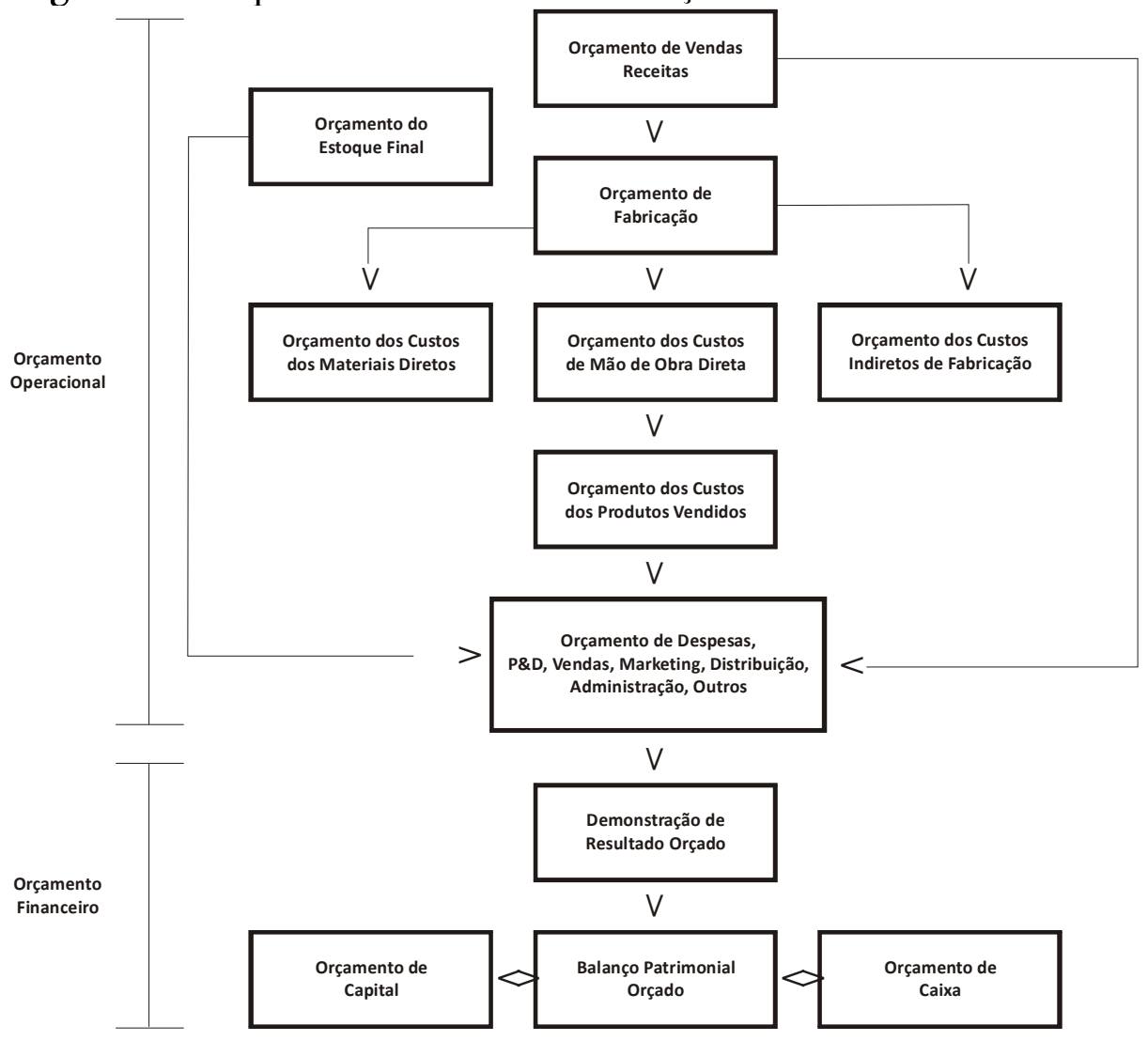

Fonte: Horngren, I997.

Modelos orçamentários - vantagens e limitações ${ }^{2}$

O orçamento é uma ferramenta de gestão que deve estar adaptada as necessidades do gestor, bem como ao contexto particular da empresa (ou do governo). É por isso, que ao longo dos anos, vários modelos orçamentários foram desenvolvidos, a fim de atingir as necessidades de cada negócio. Podemos destacar o: orçamento empresarial, contínuo, base zero, flexível, por atividade e perpétuo.

A característica principal de cada modelo é: (a) o empresarial estima recursos

2 Por questões metodológicas, nenhum modelo orçamentário - descrito neste artigo - será desenvolvido passo-a-passo. 0 objetivo é apenas oferecer uma visão geral dos processos e ciclos orçamentários.

Revista Administração em Diálogo

ISSN 2178-0080

Programa de Estudos Pós-Graduados em Administração

Pontifícia Universidade Católica de São Paulo 
tendo como base os anos anteriores;(b) o contínuo estima recursos continuadamente; (c) o base zero estima recursos da estaca zero; (d) o flexível estima recursos para vários níveis de atividade; (e) o por atividade estima recursos utilizando os direcionadores de custo e receita; e (f) o perpétuo estima recursos com base na relação causa-efeito.

As principais vantagens de cada modelo são: (a) o empresarial focaliza-se em recursos necessários para atender a demanda; (b) o contínuo focaliza-se na redução gradual de custos; (c) o base zero focaliza-se na eliminação de ineficácias do passado; (d) o flexível focaliza-se na cobrança de responsabilidade; (e) o por atividades sincroniza processos, atividades e objetos de custo; e (f) o perpétuo projeta recursos necessários para cada cliente.

Os modelos apresentam também limitações. Para cada modelo, podemos destacar: (a) o empresarial perpetua ineficiências de anos anteriores; (b) o contínuo perpetua ineficiências de anos anteriores; (c) o base zero tende a ser burocrático; (d) o flexível possui maior necessidade de entendimento dos custos; (e) o por atividades tem alto grau de complexidade na elaboração; e(f) o perpétuo, dificuldade de estabelecer a relação causa-efeito.

\section{Procedimentos para elaboração e implementação ${ }^{3}$}

Os procedimentos necessários para a elaboração e implementação do orçamento "estão divididos em três fases:(I) pré-orçamentação; (2) elaboração e execução orçamentária; e (3) acompanhamento e controle.” (LUNKES, 2003). Esse processo pode ser implantado em atividades industriais, e também em empresas de serviços.

Na Fase I (Pré-Orçamentação), a I a Etapa consiste em analisar o ambiente no qual a empresa opera, e quais os fatores-chaves levar em consideração para conduzir o negócio. Na $2^{\text {a }}$ Etapa, a empresa prepara o terreno para a elaboração e implementação do

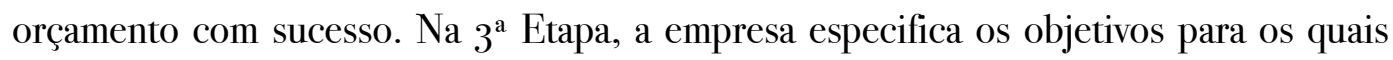
devem ser dirigidas as metas operacionais futuras. Vale lembrar, que os objetivos devem ser mensuráveis.

Na Fase 2 (Elaboração Orçamentária), a $4{ }^{\mathrm{a}}$ Etapa envolve elaborar o modelo de forma mais democrática e transparente possível, valorizando as ações e opiniões dos

3 Este tópico foi baseado no item 5.5 da tese de doutorado de LUNKES (2003). 


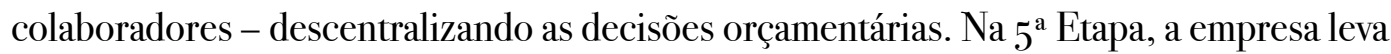
em conta mudanças nas condições futuras, principalmente relacionadas ao mercado. $\mathrm{Na}$

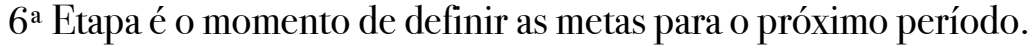

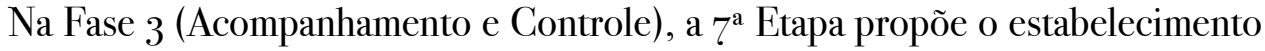
de um sistema amplo de incentivos, com o objetivo de acompanhar as metas orçamentárias. Na $8^{a}$ Etapa, as metas são coordenadas visando à integração das diferentes unidades. Por fim, na $9^{\text {a }}$ Etapa, o orçamento deve sofrer constantes aperfeiçoamentos durante o período de utilização, passando por inovações contínuas.

Orçamento base zero - conceitos e características ${ }^{4}$

Phyrr (I98I) inicia seu livro perguntando: "Por que Orçamento Base Zero? [...]" A resposta é simples: “[...] porque, anualmente, tudo começa do zero [...]” (PHYRR, 198I). O foco do processo é eliminar as imperfeições do passado. Assim,exige do administrador, um burocrático controle de “justificação" de gastos e investimentos, que devem ser baseados nos objetivos correntes do processo orçamentário.

O orçamento base zero detalha com informações a direção dada ao dinheiro e aos fins desejados. Preocupa-se em "[...] chamar a atenção para os excessos e para a duplicidade de esforço entre departamentos [...]" (PHYRR, I98I). O orçamento concentra-se nos recursos necessários para os programas, e não no aumento (ou diminuição) percentual em relação ao ano anterior.

\section{A elaboração do orçamento base zero}

Segundo Phyrr (198I), "se planejado de modo eficaz e se corretamente gerenciado, o orçamento base zero [...] é adaptável a empresas com operações, necessidades e problemas significativamente diferentes [...]". Neste processo de elaboração, é fundamental integrar o orçamento base zero ao planejamento estratégico. Ao passo que, o planejamento identifica o resultado desejado, o orçamento identifica o insumo necessário. Phyrr (I98I) completa:

4 Os demais processos orçamentários não serão desenvolvidos neste artigo, em virtude do estudo de caso (do item 3), levar em consideração apenas a aplicação prática do modelo "Base Zero". Desta forma, é fundamental abordarmos com detalhes os conceitos e as características deste modelo. Todos os aspectos explanados, neste tópico, são baseados no livro de PHYRR (1981), "Orçamento Base Zero: um instrumento administrativo prático para avaliação de despesas". O texto original, em inglês, foi publicado em 1973. 
O planejamento é mais geral do que o orçamento. O planejamento estabelece programas, metas e objetivos e toma decisões básicas de políticas para a organização como um todo (PHYRR, I98I, p. 2).

Há dois passos básicos para a elaboração do orçamento base zero: (I) a identificação de pacotes de decisão. Este passo envolve a análise e a descrição de cada atividade em separado (as atuais e as novas), em um ou mais pacotes de decisão; e (2) a priorização dos pacotes de decisão. Este passo envolve a avaliação e o escalonamento destes pacotes por ordem de importância, através da análise de custo/benefício ou de avaliação subjetiva.

Um pacote de decisão é um documento que identifica e descreve a atividade especifica de modo a que a administração possa: (I) avaliá-la e priorizá-la em relação a outras atividades que concorram para a obtenção de recursos limitados e (2) decidir aprová-la ou rejeitá-la. O pacote de decisão inclui: a finalidade (ou objetivos); as conseqüências de não executar a atividade; o desempenho; caminhos alternativos; e benefícios e custos.

Para começar a preparar seus pacotes, cada administrador identifica as atividades e operações do ano em curso. Neste momento, o gestor define seu nível de despesa previsto ou orçado para o ano em curso, além de formalizar algumas premissas como: (I) faturamento; (2) produtos a serem fabricados; (3) salários; (4) quantidade de instalações; (5) método de operação, fabricação ou elaboração do serviço; entre outras diretrizes.

O próximo passo é a priorização dos pacotes de decisão. Essa etapa é “[...] como uma técnica de alocação de seus recursos limitados, fazendo com que se concentre nas seguintes perguntas: 'Quanto devemos gastar?' 'Onde devemos gastar? "' (PHYRR, I98I). Os gestores listam, neste momento, os pacotes identificados por ordem decrescente de importância. Essas informações são lançadas no formulário de priorização. Vale ressaltar, que o formulário de priorização pode ser facilmente modificado,de acordo com as necessidades da empresa.

\section{Problemas e benefícios do orçamento base zero}

Há três requisitos essenciais para a implantação bem sucedida do orçamento base zero: (I) apoio da direção, (2) projeto eficaz e (3) administração eficaz. "O orçamento base zero é um sistema geral que pode ser adaptado com êxito às 
necessidades de atividades e organizações diferentes”. (PHYRR, I98I)

Independente desses problemas há enormes benefícios a serem obtidos pelos gestores. Um dos benefícios do orçamento base zero é a identificação da falta de coordenação entre atividades e da falta de premissas de planejamento. Além disso, em pequenas organizações, onde o alcance de controle é razoavelmente curto, o processo não precisa levar muito tempo para ser elaborado. Nas grandes empresas, o tempo gasto, será mais estendido em razão das maiores dimensões de controle e comunicação do negócio.

Phyrr (198I) considera também como beneficio, “[...] o aproveitamento de idéias e dos talentos dos administradores [...]", uma vez que, todos têm a obrigação de formular seu próprio "pacote de decisões". Por fim, não se pode esperar que o orçamento base zero resolva todos os problemas da empresa.

O orçamento base zero deve se um instrumento de identificação e avaliação eficiente das atividades e dos problemas a eles relacionados. Deve buscar minimizar os custos e reduzir as ineficiências passadas. Mas, não deve ser utilizado, como a única fonte de informação e decisão. Dessa forma, o orçamento base zero terá um efeito significativo na organização.

\section{Aplicando o Processo Orçamentário nas Decisões Financeiras}

Estudo de caso - informações da empresa

A "M\&S Comercial e Representações de Materiais Elétricos" (ou M\&S Comercial) é uma pequena empresa de intermediação comercial (ou representação comercial), que atua no fornecimento de produtos elétricos para construtoras e instaladoras elétricas e hidráulicas. Por ano, em média, a M\&S Comercial realiza vendas na ordem de R \$ 8 milhões. O market-share concentrasse em Salvador (BA), onde são realizados cerca de $98 \%$ dos negócios.

No portfólio do negócio estão relacionadas mais de I4 linhas de produtos, de fábricas diferentes, entre eles: luminária comercial, especial, industrial e pública, forros e divisórias importadas, piso elevado, luminárias de emergência, lâmpadas, reatores, fios e cabos, tubos e conexões para água quente, aquecedores de água, sistemas modulares, 
etc. Todos os produtos são fornecidos aos clientes direto da fábrica - sem a intermediação de atacadistas locais.

A empresa possui seis colaboradores (incluindo os proprietários), sendo: (I) um sócio-gerente administrativo-financeiro; (2) um sócio-gerente comercial; (3) uma secretária; e (4) dois auxiliares administrativos. O escritório fica no município de Lauro de Freitas, num ambiente próprio de $70 \mathrm{~m}^{2}$. O negócio consiste basicamente em contatos comerciais, que se convertem em cotação, e em caso de acordo com o cliente, transforma-se em pedido de compra.

O negócio antes do orçamento

Entre 2OOI e 2003, a M\&S Comercial passou por um sério problema mercadológico. Em virtude do cenário internacional recessivo e as incertezas quanto às eleições presidenciais de 2002, o mercado de construção civil sofreu uma forte retração, sobretudo no oligopolizado mercado baiano. Nesse momento, as vendas - em relação a 2000 - caíram aproximadamente 72\%, de $\mathrm{R} \$ 6$ milhões por ano para $\mathrm{R} \$$ I,6 milhões por ano (em média, entre 200 e 2003 ).

Essa situação desestruturou o fluxo de caixa e os resultados líquidos do negócio. Isso levou a empresa a ter dificuldades para honrar seus compromissos financeiros. Em virtude da ausência de um controle estratégico, a M\&S Comercial entrou num espiral declinante. Desde 200I, a empresa começou a acumular sucessivos prejuízos, culminando em 2003 num déficit líquido de $\mathrm{R} \$$ IOo mil. Na tabela I, relacionamos o resultado financeiro simplificado.

\section{Tabela 1}

Resultado Financeiro antes do orçamento (2000-2003) (em reais)

\begin{tabular}{c|c|c|r|r}
\hline Ano & Venda Bruta & Venda Líquida & \multicolumn{1}{c|}{ Despesas } & \multicolumn{1}{c}{ Resultado } \\
\hline 2000 & 6.000 .000 & 300.000 & 222.000 & 78.000 \\
\hline 2001 & 2.200 .000 & 110.000 & 120.000 & -10.000 \\
\hline 2002 & 1.200 .000 & 60.000 & 144.000 & -84.000 \\
\hline 2003 & 1.400 .000 & 70.000 & 169.200 & -99.200 \\
\hline Total & $\mathbf{1 0 . 8 0 0 . 0 0 0}$ & $\mathbf{5 4 0 . 0 0 0}$ & $\mathbf{6 5 5 . 2 0 0 , 0 0}$ & $\mathbf{- 1 1 5 . 2 0 0 , 0 0}$ \\
\hline
\end{tabular}


A ausência de planejamento e orçamento levou a M\&S Comercial quase a falência. Apesar dos esforços para reduzir os custos e as despesas administrativas, a falta de fluxo de caixa gerou uma ampliação nas despesas financeiras - uma vez que a empresa se financiava com capital de curto prazo (em geral, com taxas de juros mais altas). A situação mostrou que a empresa estava sem controle econômico, financeiro e comercial. A administração não tinha informações suficientes sobre a economia e seu mercado.

A condução do negócio se realizava por meio do "feeling" gerencial. Além disso, sua estrutura de despesas estava montada para um mercado de alta (estação), e não de baixa. Isso gerou resistência dos sócios, quando os problemas financeiros surgiram, pois não desejavam reduzir a estrutura administrativa e patrimonial. O resultado deste conjunto de decisões, entre 2001 e 2003 , foi o acumulo de déficits nos demonstrativos contábeis e no fluxo de caixa. Em 2003, a situação ficou insustentável, necessitando de uma atitude drástica dos gestores.

O negócio depois do orçamento

Em julho de 2003, a situação financeira ficou complicada, pois o capital de curto prazo se esgotou. Era fundamental, naquele momento, modificar o rumo do negócio. Sendo assim, foram implantadas novas decisões gerenciais, adaptadas ao segmento do negócio e baseadas em ferramentas estratégicas de administração - notadamente, planejamento e orçamento.

O primeiro passo foi definir a sazonalidade do negócio, para assim escolher a melhor estrutura administrativa para o negócio. Recorrendo a dados históricos, chegouse a conclusão de que o mercado de construção civil, na Bahia, possui seu "pico" entre maio e novembro. $\mathrm{O}$ auge das vendas concentrasse em agosto de cada ano. Já o pior momento das vendas, é o mês de fevereiro, em razão do carnaval e dos poucos dias úteis para se realizar negócios.

A partir daí, definiu-se a estrutura do negócio. Todas as atividades foram planejadas e estruturadas para o pior mês das vendas - fevereiro. Qualquer necessidade de ampliação será por meio de contrato temporário ou aluguel. Essas premissas estruturaram o planejamento e o orçamento empresarial. Mas, ainda faltava encontrar 
uma solução para o problema de liquidez que dificultava a condução do negócio

O fator-chave era encontrar, naquele momento, uma fonte de financiamento. A M\&S Comercial não tinha mais crédito em bancos, nem fluxo de caixa. A única saída foi vender um veículo pertencente ao sócio, no valor de R \$ 79 mil. Esse valor, com base na nova estrutura, era capaz de sustentar o negócio por pelo menos oito meses. Nesse momento, era essencial esquecer as despesas passadas e construir o novo futuro do negócio.

Sendo assim, os sócios resolveram adotar o orçamento Base Zero. Essa postura tinha o objetivo de eliminar as imperfeições do passado. Foram elaborados três pacotes de decisão - administrativo, comercial e financeiro - estipulando os gastos das atividades. O orçamento foi elaborado pela primeira vez, para o ano de 2004, levando em consideração todas as variáveis endógenas e exógenas (ou seja, da economia).

Entre 2004 e 2007, a M\&S Comercial apresentou excelentes resultados financeiros. $\mathrm{O}$ orçamento previa com antecedência possíveis déficits de caixa. Isso permitia que os gestores buscassem fontes de financiamento de longo prazo - com 45 dias de antecedência. Apesar dos problemas financeiros continuarem, e serem inerentes a qualquer tipo de negócio, as despesas financeiras reduziram em $86 \%$, em média.

O resultado é uma maior liquidez para operar e honrar com os compromissos de curto prazo. Em 2006, as dívidas acumuladas foram quitadas. Daí em diante, os gestores resolveram constituir reservas de contingência - para evitar recorrer aos bancos - no valor de R\$ Ioo mil. Com certeza, além do mercado se recuperar produtivamente, o orçamento contribuiu para a construção de uma nova fase - de profissionalismo - no negócio.

\section{As decisões financeiras antes e depois do orçamento}

Entre 2OOI e 2003, as decisões financeiras eram tomadas com base no saldo da conta corrente e no "feeling" gerencial dos sócios. Não existia planejamento, nem previsões do que poderia acontecer no futuro. Na prática, tudo girava em torno das receitas das vendas. Ou seja, se a empresa vendesse tinha dinheiro para honrar os compromissos, caso contrário, gerava um desequilíbrio financeiro - totalmente desconsiderado com antecedência pelos gestores. 
Dessa forma, as decisões financeiras não se baseavam em instrumentos estratégicos - reiterando a existência de um modelo rudimentar de negócio. Isso conduziu a empresa para a derrocada em 2003. A solução foi profissionalizar a gestão, implantando ferramentas como: o planejamento estratégico, o orçamento e os demonstrativos contábeis.

A partir de 2004, a M\&S Comercial tomou o rumo do crescimento. Com o orçamento Base Zero implantou os pacotes de decisão, com detalhamento sobre as despesas, mês a mês. Com o planejamento, montou cenários econômicos, avaliou as forças e fraquezas do negócio, mapeou os clientes e os concorrentes, e estruturou uma filosofia de acumulação de lucros.

A empresa baseava-se, então, em informações estratégicas para a tomada de decisões financeiras. Seja para investir ou financiar, as decisões passariam pelo crivo orçamentário. E, qualquer acontecimento atípico, era imediatamente avaliado e incluído nas considerações da administração. Isso conduziu o negócio a melhores resultados financeiros e comerciais. Mais tranqüilidade para trabalhar, e mais tempo para pensar em alternativas financeiras.

O resultado foi que, entre 2004 e 2007 , a M\&S Comercial apresentou bons resultados. O lucro líquido cresceu, não só em virtude da expansão do mercado, mas também em função de melhores práticas comerciais e financeiras. Nesse período, a sazonalidade foi rapidamente arrefecida com financiamentos de prazos mais longos, e reservas de contingência (acumuladas nos períodos de alta do mercado). Tudo isso, contribuiu para a sobrevivência do negócio.

\section{Os ganhos de integrar o orçamento a decisão financeira}

A integração do orçamento com a tomada de decisão financeira mostrou eficiência, na M\&S Comercial, através dos sucessivos resultados positivos. Na tabela 2, podemos verificar os resultados, entre 2004 e 2008. A partir de 2004, a M\&S Comercial começou a contabilizar lucro líquido, além de trocar o prejuízo financeiro (nãooperacional) por lucro. 


\begin{tabular}{|c|c|c|r|r|}
\hline \multicolumn{5}{|c|}{ Tabela 2 } \\
\hline \multicolumn{5}{|c|}{ Resultado Financeiro depois do orçamento (2004-2008) } \\
\hline & & & (em reais) \\
\hline & & $\begin{array}{c}\text { Custos e } \\
\text { Despesas }\end{array}$ & Resultado \\
\hline Ano & Venda Bruta & Venda Líquida & 135.600 & 9.400 \\
\hline 2004 & 2.900 .000 & 145.000 & 139.200 & 120.800 \\
\hline 2005 & 5.800 .000 & 290.000 & 1690 & 300.400 \\
\hline 2006 & 10.400 .000 & 520.000 & 219.600 & 347.400 \\
\hline & 12.300 .000 & 615.000 & 267.600 & 3400 \\
\hline 2008 & 8.600 .000 & 430.000 & 183.600 & 246.400 \\
\hline Total & $\mathbf{4 0 . 0 0 0 . 0 0 0}$ & $\mathbf{1 . 5 7 0 . 0 0 0}$ & $\mathbf{7 9 2 . 0 0 0 , 0 0}$ & $\mathbf{7 7 8 . 0 0 0 , 0 0}$ \\
\hline Fonte: M\&S Comercial & & & \\
\hline
\end{tabular}

Assim, foi possível verificar e analisar que o orçamento ajudou na gestão financeira do negócio. Isso comprova que quanto mais informações e ferramentas o gestor possuir, melhor será a sua decisão financeira. Na M\&S Comercial, todos os indicadores financeiros melhoram entre 2004 e 2008 - notadamente, rentabilidade do PL, lucro líquido, liquidez e solvência. Os ganhos de integração abriram espaço para novas conquistas mercadológicas.

\section{Considerações Finais}

Este estudo comprovou que o orçamento contribui para uma melhor gestão financeira. O estudo de caso mostrou, nos dados das tabelas i e 2, que a decisão financeira baseada no orçamento gera melhores resultados econômicos e financeiros para o negócio. Isso ocorre em virtude do orçamento prever os movimentos futuros, e equacioná-los antecipadamente através do planejamento estratégico.

Nesse instante, o gestor financeiro antecipa também suas decisões financeiras, com as estratégias e as soluções que maximizem o resultado e minimizem os custos do negócio. Essa atitude pró-ativa ajuda a empresa a aproveitar as oportunidades geradas ao longo da dinâmica do negócio. Isso permite a empresa, como por exemplo, a $M \& S$ Comercial, a utilizar melhor seus superávits do fluxo de caixa, buscando maior rentabilidade para o dinheiro. 
Após a implantação do processo orçamentário, a empresa observa os movimentos do negócio com mais consistência e profissionalismo. Além disso, coloca de lado o "feeling" e o "achismo" dos sócios, atuando com informações relevantes e estratégicas, da economia e do mercado. Com isso, a empresa é conduzida para melhores resultados líquidos. Daí em diante, os custos (oriundos da falta de planejamento) são reduzidos, sobretudo os custos financeiros não-operacionais - com juros, tarifas e impostos sobre operações financeiras.

Por fim, a condução do negócio fica mais suave e eficiente, em virtude do ambiente saudável, financeiramente. Essa integração orçamento-finanças gera ganhos estratégicos, que podem levar a empresa a uma maior competitividade no mercado de atuação - conquistando market-share. Além disso, prepara antecipadamente o negócio para novos períodos recessivos ou problemas sazonais no segmento de atuação.

\section{Referências}

ASSAF NETO, Alexandre. A dinâmica das decisões financeiras. Caderno de Estudos. São Paulo: FIPECAFI, I997.

BAUMANN, Renato. O Brasil e a Economia Global. Rio de Janeiro, Campus, 1996.

BROOKSON, Stephen. Como elaborar orçamentos. São Paulo: Editora Publifolha, 2000.

BRUNI, A.; FAMÁ, R. Decisões de Investimentos. São Paulo: Editora Atlas, 2007.

DRUCKER, Peter F. Administrando em Tempos de Grandes Mudanças. $4^{\mathrm{a}}$ Ed. São Paulo: Editora Pioneira, I998.

EICHENGREEN, Barry. Crises Financeiras - Análise, Prevenção e Gestão. São Paulo: Campus, 2003.

GITMAN, Lawrence J.; MADURA, Jeff. Administração Financeira: uma abordagem gerencial. São Paulo: Pearson: Addison Wesley, 2003.

LUNKES, R.J. Contribuição a melhoria do processo orçamentário; Florianópolis, 2003 (Tese).

MINTZBERG, Henry; AHLSTRAND, Bruce; LAMPEL, Joseph.Safari de Estrategia: um roteiro pela selva do planejamento estratégico. Porto Alegre, RS: Bookman, 2000.

MOOTT, Graham. Contabilidade para Não-Contadores. São Paulo: Makron Books, I996.

PINA, Flávia da A. S. A Dinâmica das Decisões Financeiras nos Modelos Contemporâneos das Finanças Corporativas. Feira de Santana: 2008.

PYHRR, Peter A. Orçamento Base Zero. São Paulo: Editora Interciência, I98I.

SECURATO, José R. Decisões Financeiras em Condições de Risco. São Paulo: Saint Paul Institute of Finance. 2OOI. 
SMITH, Adam. A Riqueza das Nações. São Paulo: Editora Abril, I98I.

ZDANOWICZ, José Eduardo. Orçamento Operacional. Porto Alegre: Editora Sagra, I989. 